\title{
Comparative investigation of lean effect of stator vane in hydrogen-fueled combustion turbine
}

\author{
Ryouta Nakamura ${ }^{1}$, Masaya Suzuki², Makoto Yamamoto ${ }^{3}$ \\ ${ }^{1}$ Graduate School of Mechanical Engineering, Tokyo University of Science, Tokyo, Japan \\ ${ }^{2}$ Aviation Program Group, Japan Aerospace Exploration Agency, Tokyo, Japan \\ ${ }^{3}$ Department of Mechanical Engineering, Tokyo University of Science, Tokyo, Japan
}

Email address:

j4510637@ed.kagu.tus.ac.jp(R. Nakamura),suzuki.masaya@jaxa.jp(M. Suzuki), yamamoto@rs.kagu.tus.ac.jp(M. Yamamoto)

\section{To cite this article:}

Ryouta Nakamura, Masaya Suzuki, Makoto Yamamoto. Comparative Investigation of Lean Effect of Stator Vane in Hydrogen-Fueled Combustion Turbine. International Journal of Energy and Power Engineering. Vol. 2, No. 2, 2013, pp. 77-83.

doi: 10.11648/j.ijepe.20130202.17

\begin{abstract}
In these years, a lot of environmental problems like air pollution and exhaustion of fossil fuels have been discussed intensively. In our laboratory, a hydrogen-fueled propulsion system has been researched as an alternative to conventional jet engine systems. A hydrogen-fueled propulsion system is expected to have higher power, lighter weight and lower emissions. However, for the practical use, there exist many problems that must be overcome. For example, there is little knowledge how the three-dimensional vane design affects on the flow characteristics and the aerodynamic performance of the hydrogen-fueled combustion turbine vane. The purpose of the present study is to clarify the influence of lean vanes, which is one of typical 3-dimensional design techniques, on the characteristics of the 3-dimensional flow field with hydrogen-fueled combustion within a turbine vane passage. The Reynolds-averaged compressible Navier-Stokes equations are solved with incorporating a $\mathrm{k}-\varepsilon$ turbulence and a reduced chemical mechanism models. Using the computational results for normal, compound lean and reverse compound lean vanes, the 3-dimensional turbulent flow fields with chemical reactions are visualized and investigated numerically. Through this study, it is confirmed that compound lean can suppress the excessively high temperature region on the endwall and reduce the total pressure loss.
\end{abstract}

Keywords: Computational Fluid Dynamics, Lean Vane, Turbine, Hydrogen Combustion, Jet Engine

\section{Introduction}

Recently, propulsion systems for next generation aircraft have been researched and developed over the world, while a lot of environmental problems such as air pollution and green house effect and exhaustion of fossil fuels have been discussed intensively. Many researches in several countries have been underway to develop a new propulsion system for an advanced aircraft to solve these problems. Among them, a hydrogen-fueled propulsion system is one of candidates as a substitute for a traditional jet engine system. There are some advantages in using hydrogen. Hydrogen $\left(\mathrm{H}_{2}\right)$ gas has higher energy per unit weight than conventional hydrocarbon fuels, and it has better cooling characteristics than air. Furthermore, it is beneficial that hydrogen combustion does not generate $\mathrm{SOx}$ and $\mathrm{CO}_{2}$ emissions which are the main sources of air pollution and green house effect. Besides these advantageous points, we can also clear up the exhaustion problem of fossil fuels by using hydrogen as a jet engine fuel. A hydrogen-fueled propulsion system is expected to have higher power, lighter weight and lower emissions than conventional systems. Thus, the system would be promising in future. However, for the practical use, there exist many problems that must be overcome.

Considering these backgrounds, in our laboratory, an innovative jet engine with hydrogen-fueled combustion within a turbine vane passage was proposed by Nagumo et al.[1-3]. Hydrogen gas is injected from the turbine vane surface, and the combustion is completed within the turbine vane passage. Apparently, using this concept, we can eliminate a conventional combustion chamber from a jet engine. Nagumo et al. numerically investigated this new concept, and they proved that this concept can be realizable in principle to develop a new jet engine with lighter weight, lower emissions and larger thrust. In addition, they 
performed three-dimensional computations of the flow field with chemical reactions within a first stator vane cascade (only a part of mid-span), and they found that flame sheet is formed a little away from the vane surface and thus the vane surface temperature is kept at the unburned hydrogen temperature due to the cooling effect. However, it was also indicated that the aerodynamic performance of the vane is largely degraded due to the hydrogen injection and its combustion near the vane surface. Then, Sato et al.[4] performed three-dimensional computations for the rotor/stator interaction field with hydrogen combustion. They concluded that this concept has the highest possibility by employing the hydrogen injection rate of $2 \mathrm{H}_{2} / \mathrm{O}_{2}=0.25$. Yamamoto et al.[5] studied the interaction between the secondary flow and the endwall in a linear vane cascade. They found that the surface temperature on the endwall becomes extremely high (about 3000K) because of the secondary flow pattern.

Obviously, for the purpose of realizing the concept, the turbine vane is required to have the adequate aerodynamic performance even when hydrogen is injected, and furthermore the endwall surface temperature is needed to be low enough for the heat resistance limit of the wall material. Therefore, three-dimensional vane design is important for the practical application of this concept, since hydrogen injection and secondary flows lead to significant loss in turbine cascades, and they determine the endwall surface temperature. It is well known that three-dimensional design techniques such as lean, sweep and twist change the secondary flow pattern. Hence, it is expected that the optimal three-dimensional design improve both the aerodynamic performance and the endwall temperature distribution. However, there is little knowledge how three-dimensional designs affect on the flow and combustion characteristics in the hydrogen-fueled combustion turbine.

In the present study, lean effect of the turbine stator vane in the hydrogen-fueled combustion turbine is focused on. In order to clarify the lean effect, we carry out three-dimensional numerical simulations based on the Reynolds-Averaged Navier-Stokes Simulation (RANS) and the reduced chemical reaction mechanism for combustion. Comparing the computational results for normal (i.e. linear), compound lean and reverse compound lean vanes, the three-dimensional turbulent flows around the vanes with chemical reactions are numerically investigated. Finally, it is indicated that the compound lean vane is the most promising to realize this innovative jet engine concept.

\section{Governing Equations}

The flow field is assumed to be three-dimensional, compressible, fully-developed turbulent and with chemical reactions. Therefore, the Favre-averaged continuity, NavierStokes and energy equations and the species transport equations for the chemically reacting gas are employed as the governing equations. They are expressed as follows;

$$
\begin{gathered}
\frac{\partial \bar{\rho}}{\partial t}+\frac{\partial}{\partial x_{k}}\left(\bar{\rho} \tilde{u}_{k}\right)=0 \\
\frac{\partial \bar{\rho} \tilde{u}_{i}}{\partial t}+\frac{\partial}{\partial x_{k}}\left(\bar{\rho} \tilde{u}_{i} \tilde{u}_{k}+\bar{p} \delta_{i k}\right)=\frac{\partial}{\partial x_{k}}\left(\bar{\tau}_{i k}-\overline{\rho u_{i}^{\prime \prime} u_{k}^{\prime \prime}}\right) \\
\frac{\partial \bar{\rho} \tilde{e}}{\partial t}+\frac{\partial}{\partial x_{k}}\left(\bar{\rho} \tilde{e} \tilde{u}_{k}+\bar{\rho} \delta_{i k}\right)=\frac{\partial}{\partial x_{k}}\left(\bar{\tau}_{i k} \tilde{u}_{i}-\bar{q}_{k}-\sum_{j=1}^{n} \overline{j_{j k} h_{j}}-\overline{\rho u_{k} h^{\prime \prime}}\right) \\
\frac{\partial \bar{\rho} \tilde{Y}_{j}}{\partial t}+\frac{\partial}{\partial x_{k}}\left(\tilde{u}_{k} \bar{\rho} \tilde{Y}_{j}\right)=-\frac{\partial}{\partial x_{k}}\left(j_{j k}+\overline{\rho u_{k}^{\prime \prime} Y_{j}^{\prime \prime}}\right)+\bar{w}_{j}
\end{gathered}
$$

where $\widetilde{Y}_{j}, \bar{j}_{j k}, w_{j}$ and $h_{j}$ denote the mass fraction, the diffusion flux in k-direction, the production rate per unit volume, and the specific enthalpy of species j, respectively. In the diffusion flux of species $j$, we consider only the diffusion by the concentration gradient and it can be expressed with the diffusion coefficient $D_{j}^{m}$;

$$
j_{j k}=-\bar{\rho} D_{j}^{m} \frac{\partial \tilde{Y}_{j}}{\partial x_{k}}
$$

$$
-\overline{\rho u_{i}^{\prime \prime} u_{k}^{\prime \prime}}, \overline{\rho u_{k}^{\prime \prime} h^{\prime \prime}} \text { and } \overline{\rho u_{k}^{\prime \prime} Y_{j}^{\prime \prime}} \text { are described by the }
$$
Boussinesq and the gradient diffusion hypotheses as follows;

$$
\begin{gathered}
\overline{-\rho u_{i}^{\prime \prime} u_{k}^{\prime \prime}}=\mu_{t}\left(\frac{\partial \tilde{u}_{i}}{\partial x_{k}}+\frac{\partial \tilde{u}_{k}}{\partial x_{i}}-\frac{2}{3} \frac{\partial \tilde{u}_{l}}{\partial x_{l}} \delta_{i k}\right)-\frac{2}{3} \rho k \delta_{i k} \\
\overline{\rho u_{k}^{\prime \prime} Y_{j}^{\prime \prime}}=-\bar{\rho} D_{j t} \frac{\partial \tilde{Y}_{j}}{\partial x_{k}} \\
\overline{\rho u_{k}^{\prime \prime} h^{\prime \prime}}=-\frac{\lambda_{t}}{C_{p}^{m}} \frac{\partial \tilde{h}}{\partial x_{k}}
\end{gathered}
$$

In the above equations, $D_{j t}$ and $C_{p}^{m}$ are given by using Schmidt and Prandtl numbers defined by;

$$
\begin{gathered}
\sigma_{j t}=\frac{\mu_{t}}{\bar{\rho} D_{j t}} \\
\sigma_{h t}=\frac{\mu_{t}}{\lambda_{t} / C_{p}^{m}}
\end{gathered}
$$

where both $\sigma_{j t}$ and $\sigma_{h t}$ are assumed to be unity. It should be noted that, to estimate turbulence effects, the high-Reynolds-number type $\mathrm{k}-\varepsilon$ turbulence model proposed by Launder and Spalding[6] is employed.

After verifying the chemical reaction models proposed by Huang and Chen[7], Balakrishnan and Williams[8], Sanchez et al.[9] and Chen et al.[10], 5-step reduced mechanism model proposed by Chen et al.[10] is adopted 
for calculating the source terms in the species transport equations (4). The reasons why we choose this model are that it has high predictability for chemical species concentrations and ignition characteristic, good numerical stability and relatively lighter computational load. Table 1 shows the 5-step reduced mechanism by Chen et al.[10]. As shown in the table, this model takes into account 8 species (i.e. $\mathrm{H} 2, \mathrm{O} 2, \mathrm{H} 2 \mathrm{O}, \mathrm{N} 2, \mathrm{H}, \mathrm{O}, \mathrm{OH}$ and $\mathrm{NO}$ ). The thermodynamic properties such as enthalpy and specific heat are expressed as a function of species concentration and static temperature from JANAF data[11].

Table 1. 5-step reduced mechanism by Chen et al.[10]

\begin{tabular}{llll}
\hline 1 & $\mathrm{O}_{2}+\mathrm{H}$ & $\rightarrow$ & $\mathrm{OH}+\mathrm{O}$ \\
2 & $\mathrm{H}_{2}+\mathrm{O}$ & $\rightarrow$ & $\mathrm{H}+\mathrm{OH}$ \\
3 & $\mathrm{H}_{2}+\mathrm{OH}$ & $\rightarrow$ & $\mathrm{H}+\mathrm{H}_{2} \mathrm{O}$ \\
4 & $\mathrm{H}+\mathrm{O}$ & $\rightarrow$ & $\mathrm{OH}$ \\
5 & $\mathrm{O}_{2}+\mathrm{N}_{2}$ & $\rightarrow$ & $2 \mathrm{NO}$ \\
\hline
\end{tabular}

\section{Numerical Procedures}

We originally developed an in-house code for our computations. For the numerical procedures, we employ a finite difference method because of its simplicity. In combustion process, elementary reactions have greatly different time- scales, and thus stiffness problem between the time-scale of flow and the time-scale of chemical reactions can arise in the computations. Therefore, a semi-implicit method is adopted for the time integration. That is, the chemistry source terms are implicitly calculated by Crank-Nicolson method and other terms are explicitly estimated by 2-stage Runge-Kutta method. For the spatial differences, considering the numerical stability and accuracy, 2nd-order upwind TVD scheme proposed by Yee and Harten[12] is employed for the inviscid terms, and 2nd-order central differencing scheme is used for the other terms.

\section{Computational Conditions}

\subsection{Configurations and Computational Grid}

Figure 1 illustrates the schematic diagram of the linear stator vane cascade and the computational grid system used in this study. The vane profile and the cascade geometry are quoted from the reference literature[13]. We also used this literature to check the validity of our non-reactive computational code, because the literature provides both the experimental and the computational results of the three-dimensional flow around the turbine vane. Comparing our non-reactive computational results to the experimental data, it was confirmed that our developed code has sufficient predictability to the flow. The parameters of the cascade geometry are listed in Table 2. The chord length is $51.55(\mathrm{~mm})$, the pitch is $36.0(\mathrm{~mm})$, the span length is $36.27(\mathrm{~mm})$, the inflow angle is $0(\mathrm{deg}$,) and the stagger angle is $56.0(\mathrm{deg}$.). The diameter of a hydrogen injector hole is $3.0(\mathrm{~mm})$, and the holes are put in a staggered arrangement. We allocate 5 rows of holes in the streamwise direction around the leading edge (see Figs.1 and 3 ).

Taking into account the computational load, it is too hard to resolve the complex phenomena in the vicinity of hydrogen jet injectors with a single grid system. Therefore, a structured 3-level overlapping grid system as shown in Fig. 1 is employed in our computations. With using the main grid, the computations for the whole flow field within a turbine vane passage are conducted. With Sub Grid1, which is O-type grid fitted around the vane, the boundary layer over the vane is evaluated. With Sub Grid2, the flow field around the injectors is computed. The overlapping data are interpolated linearly. A certain amount of grid points are clustered near the vane surface. The number of total grid points is approximately 680,000 . It should be noted that we checked the effect of grid resolution, using a finer grid system with about 800,000 grid points. It was confirmed that the essential flow features do not change with the finer grid system.

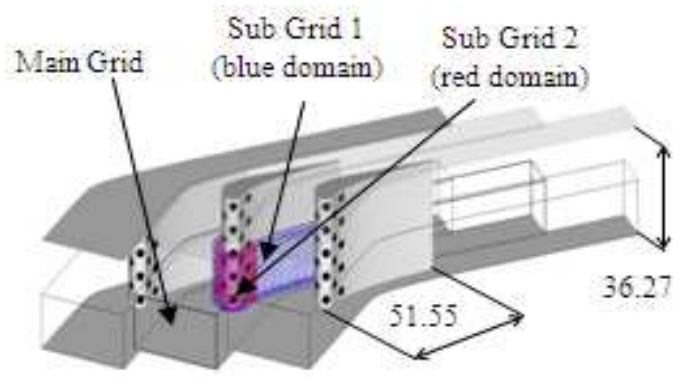

Fig 1. Schematic of turbine cascade

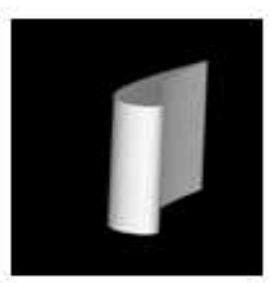

(a) Nomal

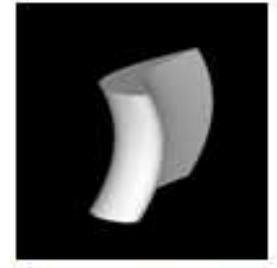

(b) Compoundlean

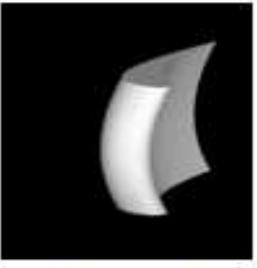

(c) Reverse compoundlean
Fig 2. Three-dimensional vane shapes

Table 2. Cascade geometry

\begin{tabular}{llc}
\hline Chord length & {$[\mathrm{mm}]$} & 51.55 \\
Pitch length & {$[\mathrm{mm}]$} & 36.00 \\
Span length & {$[\mathrm{mm}]$} & 36.27 \\
Stagger angle & {$[\mathrm{deg}]$.} & 56.0 \\
Exit angle & {$[\mathrm{deg}]$.} & 68.4 \\
Inflow angle & {$[\mathrm{deg}]$.} & 0.0 \\
Outflow angle & {$[\mathrm{deg}]$.} & 72.6 \\
Injector diameter & {$[\mathrm{mm}]$} & 3.0 \\
\hline
\end{tabular}

In the present study, we simulate the conventional linear vane (Normal), the compound lean vane (CL) and the reverse compound lean vane (RCL). The lean angle is set to be 10 degrees for the compound and the reverse compound 
lean vanes, as shown in Fig.2.

It should be noted that the half span of the vane (i.e. from the mid-span to the endwall) is computed because of the symmetry of the vane configuration.

\subsection{Flow Conditions}

In this study, we set the flow conditions on the basis of the cycle analysis of the current engine like GE90 under the taking-off condition at sea level. High-pressure (HP) air which passes through the HP compressor directly goes into the first stage of the HP turbine due to the elimination of the conventional combustor in our concept. Hydrogen-fueled combustion is completed in the first turbine vane passage. At the HP compressor exit that is just the inflow boundary of the computations, the total temperature and the total pressure of air are $903.42 \mathrm{~K}$ and 3.92 $\mathrm{MPa}$, respectively. Then the flow expands to the static pressure of $3.36 \mathrm{MPa}$ at the outflow boundary of the computational downstream domain.

Hydrogen is injected from the vane surface as the gaseous fuel. The injector holes are allocated around the leading edge as illustrated in Fig. 3. The diameter of the injector hole is $3.0(\mathrm{~mm})$ and the pitch of the holes is $3.0 \mathrm{~mm}$. This layout of injector holes has the highest feasibility among 5 cases studied in the previous study[5].

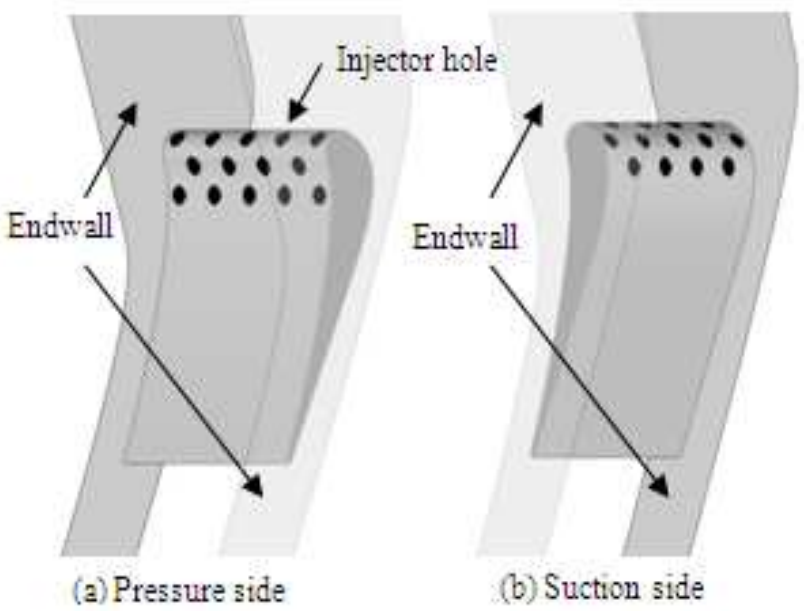

Fig 3. Injection-hole layout

In order to clarify the lean effect on the hydrogen combustion turbine, we calculate 3 cases; normal $(\mathrm{N})$, compound lean (CL) and reverse compound lean (RCL) vanes. We call them as $\mathrm{H} 2 \mathrm{~N}, \mathrm{H} 2 \mathrm{CL}$ and $\mathrm{H} 2 \mathrm{RCL}$, respectively.

The static temperature of hydrogen is fixed to be $900 \mathrm{~K}$ that is same as the static temperature of the main stream, and the direction of injection is normal to the vane surface. The amount of hydrogen injected into the flow passage is equal for each injector, and the total mass flow ratio of hydrogen to inflow air is a quarter of stoichiometric ratio. As described in Introduction, Sato et al.[4] suggested that this hydrogen injection rate of 0.25 has the highest realizability of the hydrogen-fueled combustion turbine concept.

\subsection{Boundary Conditions}

In our computation, several boundary conditions are imposed for each grid.

For the Main Grid, the following boundary conditions are applied.

- At the inflow boundary, total pressure, total temperature, chemical species and inflow angle are fixed, and in addition, Mach number is extrapolated from the computational region.

- At the outflow boundary, static pressure is fixed and other variables are extrapolated from the computational region.

- At the spanwise boundaries, symmetric condition is applied to all variables.

- $\quad$ On the endwall, no-slip and adiabatic conditions are used.

- At the circumferential boundaries, all variables are set to be periodic.

- For Sub Grid1 and Sub Grid2, the boundary conditions as listed below are imposed.

- On the vane surface, no-slip and adiabatic conditions are used, and the general wall function for turbulent quantities is employed.

- At the hydrogen jet boundary, the static pressure of jet is extrapolated from the main stream, and other variables are fixed by the specified values.

- $\quad$ At the mid-span boundaries, symmetric condition is applied to all variables.

- $\quad$ On the endwall, no-slip and adiabatic conditions are used, and the general wall function for turbulent quantities is applied.

- At the circumferential boundaries, all variables are set to be periodic.

\section{Numerical Results and Discussion}

\subsection{Flow Field}

Figures 4 and 5 indicate the static temperature distributions on the suction side of the stator vane and the endwall surface, and the hydrogen $\left(\mathrm{H}_{2}\right)$ mole fraction distributions in the cross-sections of the flow passage, respectively. And Fig.6 exhibits the streamlines viewed from the downstream, and the color denotes the flow speed.

First, we focus on the normal vane H2N (see Figs. 4(a) and 5(a)). It is clear that the hydrogen injected from each injector hole produces low temperature region downstream of the hole, most of the vane surface is kept at low temperature, but high temperature region appears near the endwall and especially the downstream of the vane. From the $\mathrm{H}_{2}$ mole fraction distributions, it can be seen that uniform film of unburned hydrogen is formed over the vane surface, and combustion occurs along the interface between this uniform film and the main stream air. It is apparent that the high temperature region is caused from the combustion 
on the interface and the secondary flow.

The static temperature and $\mathrm{H}_{2}$ mol fraction for the compound lean vane $\mathrm{H} 2 \mathrm{CL}$ are exhibited in Figures. 4(b) and $5(\mathrm{~b})$. The characteristics are similar to those of the normal vane (Figs. 4(a) and 5(a)). However, in this case, it is clear that high temperature region moves towards the mid-span, and the extremely high temperature region on the downstream endwall disappears. Obviously, this trend comes from the secondary flow motion (see Fig. 6(b)). That is, the compound lean effect makes the passage vortex go towards the mid-span. From these results, we can suggest that compound lean is preferable for suppressing the high temperature region on the endwall.

Figures 4(c) and 5(c) show the same distributions for the reverse compound lean vane H2RCL. Apparently, the unburned hydrogen is accumulated near the suction side endwall, and the combustion takes place along the curved interface. This is caused from the behavior of secondary flow, again (see Fig. 6(c)). A strong passage vortex is generated in the passage, and it goes towards the endwall near the trailing edge due to the reverse compound lean effect. The accumulated hydrogen remarkably enlarges the high temperature region on the downstream endwall.

Fig.7 shows the top view of static temperature distributions on the endwall. We can find that high temperature region exists over the wide area downstream of the vane in the cases $\mathrm{H} 2 \mathrm{~N}$ and H2RCL. On the contrary, high temperature region is suppressed in the case H2CL. Apparently, this comes from the compound lean effect. Therefore, in the point of surface temperature, compound lean is the most promising in the hydrogen-fueled combustion turbine.
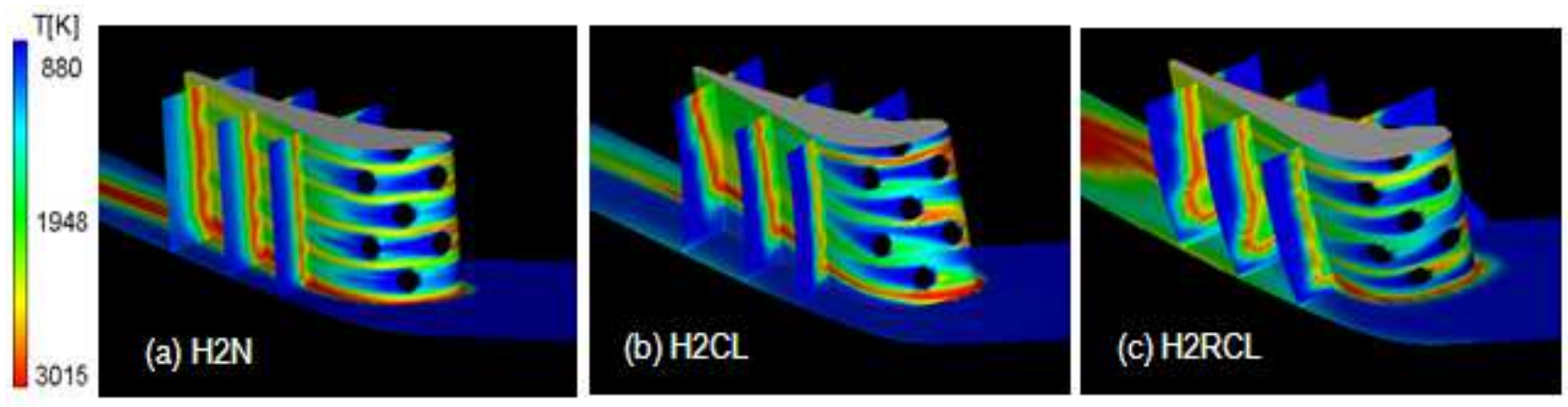

Fig 4. Static temperature distributions
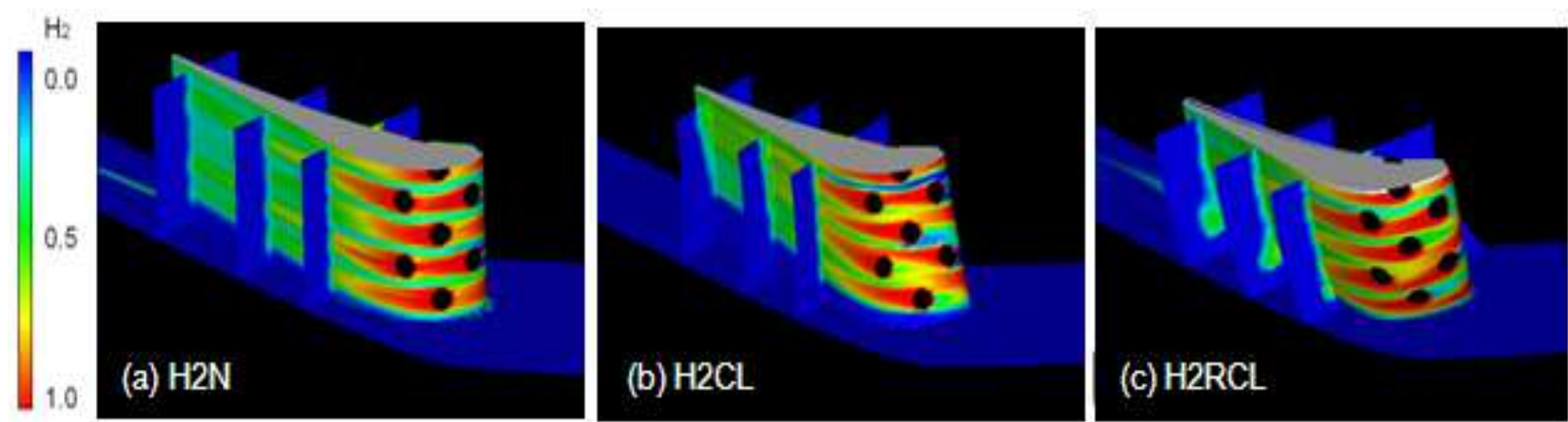

Fig 5. H2 mol fraction distributions
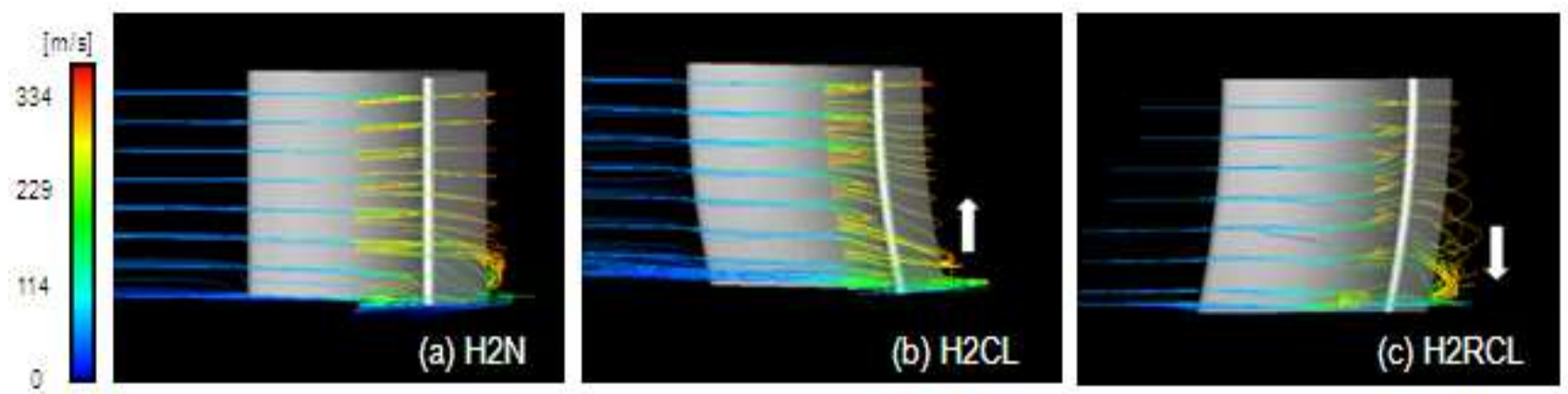

Fig 6. Streamlines 

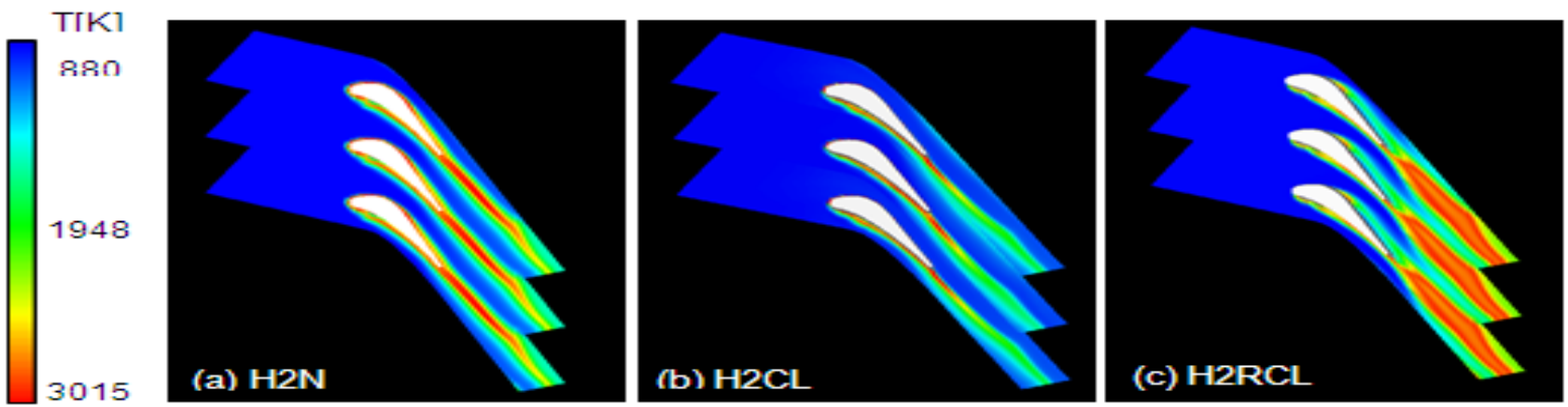

Fig.7 Static temperature distributions on endwall

\subsection{Aerodynamic Performance}

This section discusses how aerodynamic performance changes due to the hydrogen injection from the vane surface and the combustion phenomena.

Fig. 8 shows the comparison of surface pressure coefficient $C_{p}$ versus $x / C_{x}\left(C_{x}\right.$ : axial chord length) at the mid-span section of the vane. In the figure, the black, red and blue line represents the result for $\mathrm{H} 2 \mathrm{~N}, \mathrm{H} 2 \mathrm{CL}$ and $\mathrm{H} 2 \mathrm{RCL}$ case, respectively. The surface static pressure coefficient $C_{p}$ is defined by the following equation;

$$
C_{p}=\frac{P_{s}-P_{s 2}}{P_{t 1}-P_{s 2}}
$$

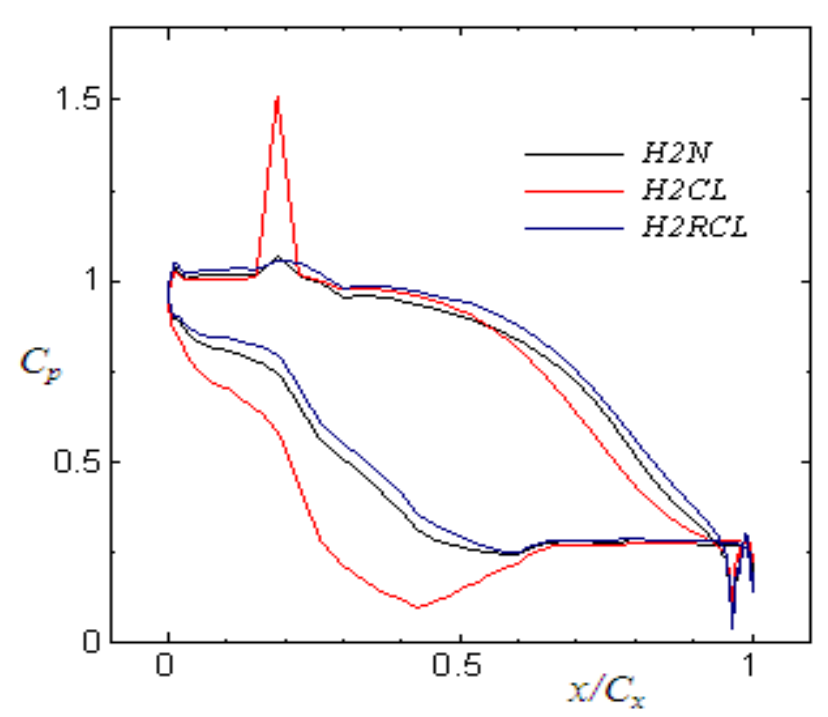

Fig 8. Surface static pressure coefficients

Here, $P_{s}, P_{t 1}$ and $P_{s 2}$ are the local surface pressure, the inflow total pressure and the outflow static pressure. From this figure, it can be confirmed that the compound lean vane $\mathrm{H} 2 \mathrm{CL}$ has the best aerodynamic performance, while the reverse compound lean vane H2RCL has the worst one. This is caused from the secondary flow pattern. That is, the secondary flow in H2RCL makes the main stream go towards the endwall, and thus the flow speed at the mid-span becomes relatively small. This low speed over the suction surface makes the aerodynamic performance be worse. It should be noted that, in the H2CL case, we can see the peaky pressure coefficient on the pressure side at about $0.2 C_{x}$. The reason for this result is that the peak position just corresponds to the injection hole.

Fig.9 exhibits the total pressure distributions at the 0.1 chord downstream cross-section from the trailing edge. We can find that the secondary flow increases the total pressure loss near the endwall of the suction side in the $\mathrm{H} 2 \mathrm{~N}$ case and especially in the H2RCL case. On the other hand, the total pressure loss due to the secondary flow is effectively suppressed in the H2CL case. In the point of energy loss, the compound lean vane is preferable to others.

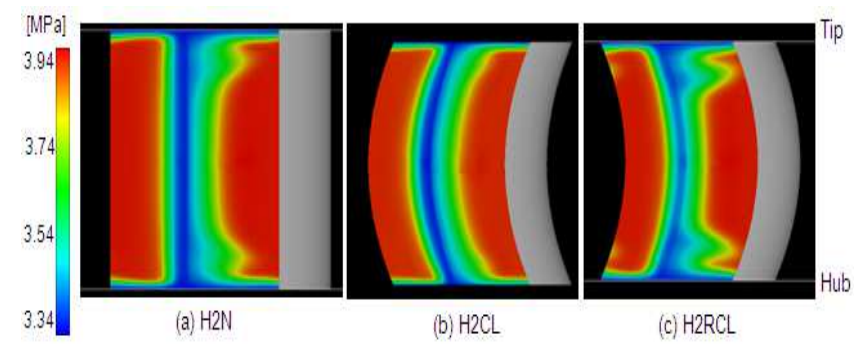

Fig 9. Total pressure distribution at 0.1 chord downstream section from trailing edge

\section{Conclusion}

We performed three-dimensional numerical simulations of the flow fields with chemical reactions within a turbine vane passage, in order to realize the innovative jet engine concept. Comparing the numerical results for the linear, the compound lean and the reverse compound lean vanes, the lean effect in terms of secondary flow structure, surface temperature and aerodynamic performance are investigated. The obtained insights can be summarized as follows;

- The compound lean vane can prevent the passage vortex from developing, and it can suppress the secondary flow even in the hydrogen-fueled combustion turbine.

- The compound lean vane can effectively suppress the static temperature on the endwall. This is favorable for realizing the hydrogen-fueled combustion turbine concept.

- On the contrary, a strong secondary flow which goes towards the endwall exists in the reverse compound lean vane case. This secondary flow produces the extremely high temperature region on the endwall 
and especially on the downstream of the vane.

In our future work, we have to optimize the vane shape and the layout of hydrogen injector holes, because we conducted only a kind of sensitivity analysis for the lean effect in the present study.

\section{Nomenclature}

$C_{p} \quad$ surface static pressure coefficient

$C_{x} \quad$ axial chord length

$D \quad$ diffusion coefficient

e total energy per unit volume

$h_{j} \quad$ specific enthalpy of species $j$

$j_{j k} \quad$ diffusion flux of species $j$ in direction $k$

$k \quad$ turbulent kinetic energy

$p \quad$ static pressure

$P_{s} \quad$ local static pressure

$P_{t 1} \quad$ inflow total pressure

$P_{s 2} \quad$ outflow static pressure

$q_{k} \quad$ heat flux in direction $k$

$t \quad$ time

$u_{i} \quad$ velocity component in direction $x_{i}$

$w_{j} \quad$ production rate for species $j$

$x_{i} \quad$ Cartesian coordinate in direction $i$

$Y_{j} \quad$ mass fraction of species $j$

$\delta_{i j} \quad$ Kronecker delta

$\mathcal{E} \quad$ dissipation rate of $k$

$\rho \quad$ density of fluid

$\tau_{i k} \quad k$ directional flux of $i$ directional momentum

\section{References}

[1] T.Nagumo, K.Toda and M.Yamamoto, 2001, Computation of hydrogen-fueled combustion within turbine blade passage, Transaction of JSME, Ser.B, Vol.67, No.659, pp.1672-1679

[2] T. Nagumo, K.Toda and M.Yamamoto, 2000, Numerical investigation of hydrogen-fueled combustion within turbine blade passage, Proceeding of ISROMAC-8, Vol. 2, pp.841-848
[3] T.Nagumo, K.Toda and M.Yamamoto, 2001, Threedimensional computations of hydrogen-fueled combustion within turbine blade passage, AIAA Paper 01-16489

[4] M.Sato, T.Nagumo, K.Toda and M.Yamamoto, 2003, Computation of rotor/stator interaction with hydrogen-fuelled combustion, Proceedings of 2003 Joint ASME/JSME Fluids Engineering Conference, ASME FEDSM2003-45618, pp.1-6

[5] M.Yamamoto, J.Ikeda and K.Inaba, 2006, 3D computation of hydrogen-fueled combustion around turbine blade (Effect of arrangement of injector holes), Journal of Thermal Science, Vol.15, No.3, pp.233-239

[6] B.E.Launder and D.B.Spalding, 1974, The numerical computation of turbulent flows, Computer Methods in Applied Mechanics and Engineering, Vol.3, pp.269-289

[7] L.W.Huang and C.H.Chen, 1997, Droplet ignition in a high-temperature convective environment, Combustion and Flame, Vol.109, pp.145-162

[8] G.Balakrishnan and F.A.Williams, 1994, Turbulent combustion regimes for hypersonic propulsion employing hydrogen-air diffusion flames, Journal of Propulsion and Power, Vol.10, pp.434-437

[9] A.L.Sanchez, G.Balakrishnan, A.Linan and F.A.Williams, 1996, Relationship between and numerical analyses for ignition of hydrogen-air diffusion flames, Combustion and Flame, Vol.105, pp.569-590

[10] J.Y.Chen, W.C.Chang and M.Koszykowski, 1995, Numerical simulation and scaling of NOx emissions from turbulent hydrogen jet flames with various amounts of helium dilution, Combusion. Science and Technology, Vol.110, No.111, pp.505-529

[11] D.R.Stull and H.Propet., 1985, JANAF Thermochemical Tables, 3rd edition, U.S. Dept. Commerce, Washington.

[12] H.C.Yee and A.Harten, 1987, Implicit TVD schemes for hyperbolic conservation laws in curvilinear coordinates. AIAA Journal, Vol.3, pp.266-274

[13] The Japan Society of Mechanical Engineers, 1994, Numerical analysis of the flow around a blade cascade and verification, RC104 Section committee reports of the flow analysis program verification, pp.198-230. 